\title{
Light: an experiments based learning approach with primary school children
}

\section{Cátia Abreu, Silvana Noversa, Paulo Varela, Manuel Costa}

Cátia Abreu, Silvana Noversa, Paulo Varela, Manuel F. Costa, "Light: an experiments based learning approach with primary school children," Proc. SPIE 9289, 12th Education and Training in Optics and Photonics Conference, 92892N (17 July 2014); doi: 10.1117/12.2070751

SPIE Event: 12th Education and Training in Optics and Photonics Conference, 2013, Porto, Portugal 


\title{
Light. An experiments based learning approach with primary school children
}

\author{
Cátia Abreu ${ }^{\text {a }}$ Silvana Noversa ${ }^{a}$; Paulo Varela ${ }^{b}$; Manuel Filipe Costa ${ }^{c}$ \\ ${ }^{\mathrm{a}}$ Preschool teachers/master students \\ ${ }^{\mathrm{b}}$ Institute of Education, University of Minho, Campus de Gualtar, 4710-057 Braga, Portugal, \\ 'Centro de Física, University of Minho, Campus de Gualtar 4710-057 Braga, Portugal \\ pibvarela@ie.uminho.pt; mfcosta@fisica.uminho.pt
}

\begin{abstract}
A pedagogical intervention project was carried out at a primary school in the municipality of Vila Verde, Braga in Portugal. In a class of the $3^{\text {rd }}$ grade, composed of 16 students, a practice of inquiry-based science teaching was implemented, addressing the curricular topic "Light Experiments". Various experimental activities were planned within this topic, including: What is light? How does light travel? Does light travel through every material? How is light reflected by a mirror?

This project adopted an action research methodology and had as its main objectives: a) to promote a practical and experimental approach to the science component of the Environmental Studies curricular area; b) to describe the scientific meaning construction process inherent to the topics addressed in the classroom with the children, c) to assess the learning steps and children' achievements. Class diaries were prepared, based on field notes and audio recordings taken in the classroom. Through the analysis of the class diary concerning the topic "materials that let light travel through them" we intend to illustrate the process of construction of scientific meanings promoted in the classroom with our approach.
\end{abstract}

Keywords: Collaborative and Reflexive Learning, Inquiry-Based Science Education, Light, Transparency, Primary education.

\section{INTRODUCTION}

In science teaching, one of the approaches that have been suggested by the science curricula of many countries and by some international organizations is inquiry-based science teaching. Inquiry teaching is the "intentional process of diagnosing problems, critiquing experiments and distinguishing alternatives, planning investigations, researching conjectures, searching for information, constructing models, debating with peers, and forming coherent arguments” [1, p. 4]. The National Research Council [2] identifies five attributes that learners will acquire from inquiry-based science teaching: a) engaging in scientifically oriented questions; b) giving priority to evidence in answering questions; c) formulating explanations based on evidence; d) connecting explanations to scientific knowledge, and e) communicating and justifying explanations. According to Drayton and Falk [3, p. 25], "The inquiry-based approach to science education [...] introduces students to science contents, including the process of investigation, in a context of reasoning, which gives science its dynamic nature and provides the logical framework that enables the understanding of scientific innovation and the evaluation of scientific claims. Inquiry is not process versus content; it is rather a way of learning content”. Inquiry teaching is an approach that enables the learning of concepts and the development of scientific processes [4]. Scientific inquiry encourages the development of problem solving, communication and thinking skills, as students pose questions about the natural world and then seek evidence to answer their questions [5]. The ability to question, hypothesize, design investigations and develop conclusions based on evidence gives all students the problem-solving, communication, and thinking skills they will need to claim their place in the $21^{\text {st }}$ century world [2]. In this sense, one skill that all students should acquire is the ability to conduct an investigation where they keep everything else constant while changing one single variable. This ability provides a powerful general strategy for solving many problems encountered in the workplace and in everyday life [2, pp. 14-15]. 
However, in the majority of European countries, the reality of classroom practice is that these methods are being implemented by relatively few teachers [6] [7]. Reports from the European Commission continue to advocate the advantages of inquiry-based science education and its recommendations clearly promote the use of inquiry-based science teaching in Europe [8].

In Portugal, the situation is no different. Although the science curriculum of primary education suggests a teaching practice in which students should be "active observers, with the ability to discover, investigate, experiment and learn" [9, p. 102], this teaching practice is still only occasional, with only a residual expression in the teachers' pedagogical practices [10]. In light of this, the present study was conducted - a pedagogical intervention project in the field of science teaching, aimed at promoting an approach to science education based on an active and constructive role for the student, in a context of social interaction with peers and with the teacher [11] [12].

\section{OBJECTIVES}

In this context, a pedagogical intervention project was developed, which incorporates the practice of inquiry-based science teaching, addressing the theme "Light Experiments", of the "Environmental Studies" curricular area of primary education. More specifically, this article intends to describe and illustrate the process of construction of scientific meanings around the topic "materials that allow light to travel through them", addressed in the classroom.

\section{METHODOLOGY}

The study adopted an action research approach. A pedagogical intervention in science teaching was carried out with a class of the 3rd year, at a school located on the outskirts of the city of Braga - Portugal. The class was composed of 16 students, 10 boys and 6 girls, aged 7 to 8 years. For two months, 7 lessons were taught on the curricular topic "Light Experiments", amounting to a total of 15 hours of intervention in the classroom, as presented in the following table:

Table 1. Lessons subject and duration.

\begin{tabular}{|c|c|}
\hline Lesson subject & Duration \\
\hline 1. What is light? Why can't we see objects in the dark? & 2 Hours \\
\hline 2. How does light travel? & 2 Hours \\
\hline 3. Which materials let light travel through them? & 2 Hours \\
\hline 4. Reflection of light & 2 Hours \\
\hline $\begin{array}{l}\text { 5. How does the direction and length of shadows vary with the } \\
\text { position of the sun throughout the day? }\end{array}$ & 3 Hours \\
\hline 6. Does the height of an object influence the length of its shadow? & 2 Hours \\
\hline $\begin{array}{l}\text { 7. Does the distance between the light source and an object have } \\
\text { an influence on the length of its shadow? }\end{array}$ & 2 Hours \\
\hline Total & 15 Hours \\
\hline
\end{tabular}

For each topic addressed, a teaching and learning plan was prepared, containing the following elements: i) learning goals; ii) materials needed in order for the groups to implement the planned activities; iii) guidelines for the teaching and learning process, and iv) an individual record sheet for each student. Each lesson, which corresponds to an action research cycle, begins with a teaching and learning plan, which is implemented flexibly, according to the teaching and learning processes generated and promoted in the class reality. The lessons were taught by the two authors of this poster, who, in collaboration with the class teacher, played the role both of researchers and teachers.

The data generated in the intervention was collected using two complementary methods: the field notes made by the researchers and the audio recordings of the lessons. This raw data was later compiled in the form of detailed narratives of the most relevant events that took place in the classroom - the class diaries. These constituted the principal method of recording data and, simultaneously, a strategy for reflection and for the modelling of the teaching and learning process 
[13] [14]. Additionally, tests were conducted to evaluate the learning acquired by the students and a questionnaire was proposed to parents/guardians, aiming to collect comments and reactions, expressed by the students in the family context, concerning the intervention carried out in class.

\section{SOME RESULTS}

The data obtained from the various collection methods used is still under treatment and analysis. However, based on the analysis of the class diary concerning "materials that allow light to travel through them", we present the process of construction of scientific meanings promoted in the classroom.

\subsection{Content analysis of the class diary}

In small collaborative groups, the students investigate which materials allow light to travel through them and which do not. The lesson begins with the following question:

\section{A. Do materials allow light to travel through them? Can light travel through all materials? What do you think?}

- $\quad$ The students communicate their ideas.

"Yes, because that box is transparent and light goes inside it, but light can't go into all objects" (Leonardo). Other students state: "Yes, because light passes through the window" (Joel); "light is entering through the window and then there is light in here” (Bruna); "it can’t go through a wall, for example” (Gonçalo); "it can't go through this book" (Diogo S.). "I think light goes through everything" (Bruna). "Light goes through some objects and through others it doesn't” (Joel); "light goes through certain materials but not through others” (Francisca); “it can't travel through some materials” (Ângelo).

\section{B. What can we do to see if light travels through a material or not?}

- $\quad$ Students suggest ways to test their ideas.

The students suggest ways to test their predictions: Ângelo says: “we'll put a light in front of a paper to see if it goes through it”; "we'll need paper and a flashlight; we'll point the flashlight at the paper and then we'll see if it goes through it” (Guilherme).

\section{What do we need to do to see if light can travel through this sheet of cardstock? \\ - In groups, students carry out practical procedures and make observations.}

Students suggest experimenting. The groups are given some materials. They turn on the flashlight and begin by testing it on a sheet of cardstock. After all have experimented, I ask: "What happened?" "We pointed the flashlight at the cardstock and the light did not go through" (Daniela); "we see the light on one side, but it doesn't go through to the other” (Eva); “it (light) can't go through, because it didn't appear on the other side, on the wall, as it did before” (Bruna). The groups concluded that light does not pass through the sheet of cardstock.

\section{What will happen if you use a sheet of acetate or tracing paper?}

\section{- $\quad$ They elaborate and justify their predictions.}

The groups are unanimous in predicting that light will pass through the sheets of acetate and tracing paper: "with the acetate sheet, it will go through, and we will be able to see it better; with the tracing paper, we won't see it as well, but it will also go through" (Lara); "the light will pass through both” (Joel); “on the transparent sheet (acetate) we'll see it better and on the other (tracing paper) we'll see only a little” (Diogo S.); "with the acetate sheet, light will go through much better than with the other” (Eva).

\section{- $\quad$ The groups test their predictions and make observations.}

"What happened when you pointed the flashlight at the sheet of acetate paper and tracing paper?" - I ask. "It goes through both" (Bruna); "my idea was correct” (Eva); "it goes through both, but with acetate, light passes through more easily" (Joel); "with the acetate sheet, we can see the light better than with the other paper” (Diogo S.); "light passed through both sheets, but it passed more easily through acetate because it is transparent” (Simão); “a weaker light passed 
through the tracing paper” (Ângelo); “with the tracing paper, light wasn't as strong” (Francisca); “with the tracing paper, less light went through because acetate is transparent and the other is not” (Diogo M.).

\section{E. Introduction of the terms transparent, translucent and opaque.}

- $\quad$ They learn and apply the new terms to the meanings constructed.

When asked what the word "transparent" means, João answers: "it means that all light goes through from one side to the other". "What differences have you found between acetate, which is a transparent material, and the tracing paper?" - I ask. "Tracing paper is not transparent” (Bárbara); "with tracing paper, light passes through, but not all of It” (Francisca); "it doesn't go through as well because one is transparent and the other is a very light colour” (Joel). I refer that materials that only allow part of the light to pass through them are called "translucent". Leonardo comments: "tracing paper is translucent because it is not transparent, you can't really see the light on the other side very well”. "And cardstock, what type of material do you think it is?” - I ask. Eva replies: “it didn't let light go through”. I refer that materials that do not let light pass through them are called "opaque”.

\section{F. Introduction and identification of new materials.}

The children, in groups, are encouraged to apply the above mentioned new meanings - transparent, opaque and translucent - to new materials. For this, the groups are given new materials: cardboard, a cellophane sheet, a piece of cloth, colourless plastic bags, a thin white plastic plate, a mirror, a napkin and a colourless glass tumbler. The groups count the materials and identify them.

\section{G. Do these materials allow light to travel through them?}

The groups present their predictions to the class. Example of group 1:

- Transparent materials: colourless glass tumbler, colourless plastic bag, acetate sheet and cellophane sheet.

- Opaque Materials: Cardboard, cardstock, mirror, napkin, white plastic plate.

- Translucent materials: tracing paper, fabric.

\section{H. What should we do to find out if the groupings you made are correct?}

Students test their predictions and record their observations on a chart (table 2.

Table 2. Observation recording chart.

\begin{tabular}{l|c||c|c}
\multicolumn{1}{c}{ Material } & Transparent & Translucent & Opaque \\
\hline Tracing paper & & $\times$ & \\
\hline Cardstock & & & \\
\hline Cardboard & & $\times$ & \\
\hline Cellophane sheet & & & \\
\hline Fabric & & & \\
\hline Glass tumbler & $\times$ & & \\
\hline White plastic plate & & & \\
\hline Mirror & & & \\
\hline Coloured acetate & & & \\
\hline Napkin & & & \\
\hline Colourless plastic bag & & & \\
\hline
\end{tabular}

- $\quad$ They reflect on it and report their observations to the class

The predictions made for some of the materials do not coincide with evidence. The groups conduct new tests on the materials for which their predictions were wrong. During this process, they become aware that: a) cellophane is a "translucent” material, "because less light goes through it” (Leonardo); b) the mirror "is not transparent” (Lara); "when we look in the mirror, we see ourselves, but we do not see what's on the other side. So, it is not transparent, light does not pass to the other side” (Daniela); c) the paper napkin and the white plastic plate are "translucent, because we put our hands behind the plate and we could see them a little” (Bruna); "we unfolded the napkin completely and then we could 
see a bit through it. It was like tracing paper, which is translucent” (Eva); "the plate is translucent, because you can see some shadows” (Bruna).

\section{Then what are transparent, translucent and opaque materials?}

- $\quad$ The children collectively construct a sentence for each meaning - transparent, translucent and opaque materials.

The groups give contributions for the collective construction of the meanings of transparent, translucent and opaque materials: Students record the individual meanings consensually constructed in the class:

"Transparent materials let all light pass through and, therefore, we can see clearly through them".

"Opaque materials do not let light pass through and, therefore, we cannot see what's on the other side"

"Translucent materials let some light pass through. Through them, we cannot see what is on the other side very well, we can only see shadows and darker colours."

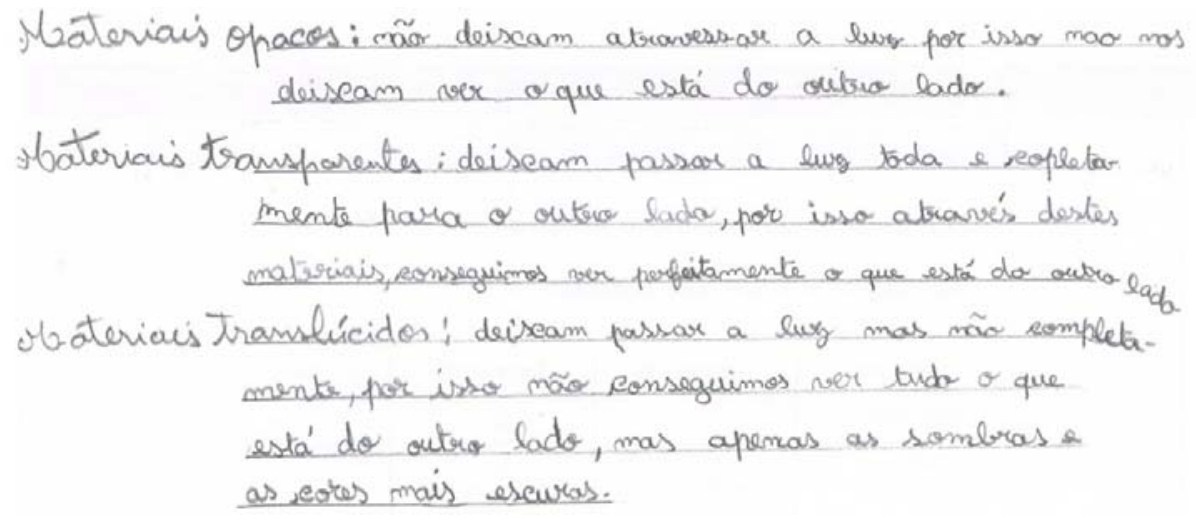

Figure 1. Recording of the individual meanings constructed.

\section{J. What can we say about the passage of light through different materials?}

- $\quad$ They conclude that light does not pass through all materials.

The students conclude that light only travels through transparent and translucent materials and that the latter let through only part of the light: "light only passes through some materials” (Lara). "Which materials?” - I ask. "Transparent and translucent” (several); "more through transparent and less through translucent” (Lara); "with opaque materials, no light passes through" - adds Eva. "What happens to light in opaque materials?” - I ask. "Light does not pass through any opaque materials" (Luís); "in the mirror, light even comes back” (Lara); "light is reflected back” (Joel); "light hits an opaque material and it does not pass through to the other side" (Daniela); "it even made a shadow when put it in front of the board” (Gonçalo). "So, what is formed on the other side of the object?” - I ask. "A shadow” - Several students reply.

\section{FINAL CONSIDERATIONS AND CONCLUSION}

The analysis of the class diary on "materials that allow light to travel through them" reveals that students aged 7/8 years are able to take on an active and reflective role in learning activities, when these are approached in a collaborative context, of stimulation and freedom to express their thoughts. In the studied case, students: a) begin by communicating their personal ideas on whether or not light travels through all materials; b) suggest ways to test those ideas; c) conduct tests, in groups, with a sheet of cardstock; d) develop and test predictions about whether or not light can travel through a sheet of acetate and a sheet of tracing paper; e) make the corresponding observations; f) learn new words for the meanings constructed - "transparent", "translucent" and "opaque"; g) apply those meanings to new materials and separate 
the materials into three groups, according to the respective predictions; $h$ ) test the new predictions and record the observations in a chart; i) collectively construct sentences around the meanings, now deeper and more elaborate, of transparent, translucent and opaque materials; j) individually record the learning acquired.

All throughout this learning process, the meanings that students gradually construct, through physical interaction with the materials, are subject to collective discussion and reflection, in a context of social interaction [15], aiming at the construction of socially enriched meanings, shared by a growing number of students. Through "reflective questioning", the teacher stimulates the students' thoughts and actions [10], supporting and guiding the individual and collective cognitive activity of the students, helping them climb progressively higher levels of learning. All this, as supported by Sá [10] and Harlen [4] [12], entails great personal and intellectual involvement by the student and is closely associated to an intervention intentionally guided by the teacher, which aims at promoting in students both the construction of meanings that are more consistent with reality and the development of scientific skills.

\section{ACKNOWLEDGMENTS}

This work was partially supported by FEDER through the COMPETE Program and by the Portuguese Foundation for Science and Technology (FCT) in the framework of the Strategic Project PEST-C/FIS/UI607/2011.

\section{REFERENCES}

[1] M. C. Linn, E. A. Davis and P. Bell, Internet environments for science education, London: Lawrence Erlbaum, 2004.

[2] National Research Council, "Inquiry and the national science education standards: A guide for teaching and learning," National Academy Press, Washington, DC, 2000.

[3] B. Drayton and J. Falk, "Tell-tale signs of the inquiry-oriented classroom," NASSP Bulletin, vol. 85, no. 623, pp. 2434, 2001.

[4] W. Harlen, "Evaluating Inquiry-Based Science Developments.,” 11 May 2004. [Online].

[5] P. Cuevas, O. Lee, J. Hart and R. Deaktor, "Improving Science Inquiry with Elementary Students of Diverse Backgrounds," Journal of Research in Science Teaching, vol. 42, no. 3, pp. 337-357, 2005.

[6] F. Abd-El-Khalick, S. Baujaoude, R. Duschl, N. G. Lederman, R. Mamlok-Naaman and A. Hofstein, "Inquiry in science education: International perspectives," Science Education,, vol. 88, no. 3, pp. 397-419, 2004.

[7] K. Kask and M. Rannikmäe, "Towards a model describing student learning related to inquiry based experimental work linked to everyday situations," Journal of Science Education, vol. 10, no. 1, pp. 15-19, 2009.

[8] B. Cavas, "The meaning of and need for "Inquiry Based Science Education (IBSE)," Journal of Baltic Science Education, vol. 11, no. 1, pp. 4-6, 2012.

[9] ME, "Organização Curricular e programas Ensino Básico - $1^{\circ}$ Ciclo," Ministério da Educação. Departamento de Educação Básica, Mem Martins, 2004.

[10] J. Sá, Renovar as Práticos no $1^{\circ}$ Ciclo Pela Via das Ciências da Natureza, Porto: Porto Editora, 2002.

[11] S. Larkin, "Collaborative Group Work and Individual Development of Metacognition in the Early Years," Research in Science Education, vol. 36, pp. 7-27, 2006.

[12] W. Harlen, Enseñanza y aprendizaje de las ciencias. (2 ${ }^{\mathrm{a}}$ ed. atualizada), Madrid: Ediciones Morata, 2007.

[13] J. G. Sá, "Diary Writing: An Interpretative Research Method of Teaching and Learning," Educational Research and Evaluation, vol. 8, no. 2, pp. 149-168, 2002.

[14] M. A. Zabalza, Diarios de clase: un instrumento de investigación, Madrid: Narcea, 2004.

[15] V. E. Ibáñez and I. G. Alemany, "La interacción y la regulación de los procesos de enseñanza-aprendizaje en la clase de ciencias: análisis de una experiencia," Enseñanza de Las Ciencias, vol. 23, no. 1, pp. 97-110, 2005. 